\title{
1 Nonthermal Inactivation of Norovirus Surrogates on Blueberries using Atmospheric
}

\section{Cold Plasma}

3 Alison Lacombe ${ }^{1}$, Brendan A. Niemira ${ }^{2 *}$, Joshua B. Gurtler ${ }^{2}$, Joseph Sites ${ }^{2}$, Glenn Boyd ${ }^{2}$,

4 David H. Kingsley ${ }^{3}$, Xinhui $\mathrm{Li}^{4}$, and Haiqiang $\mathrm{Chen}^{4}$.

5 1) National College of Natural Medicine, 014 SE Porter St., Portland OR 97201

6 2) U.S. Department of Agriculture, Agricultural Research Service, Food Safety and

7 Intervention Technologies Research Unit, Eastern Regional Research Center, 600

$8 \quad$ Mermaid Ln, Wyndmoor, PA, 19038.

9 3) U.S. Department of Agriculture, Agricultural Research Service, Food Safety and

10 Intervention Technologies Research Unit, Delaware State University, Dover, DE

$11 \quad 19901$

12 4) Department of Animal and Food Sciences, University of Delaware, 020

13 Townsend Hall, Newark, DE, 19716

$15 *$ Corresponding author

16 Brendan.Niemira@ars.usda.gov

17 Phone: (215) 233-6583

18 Fax: (215) 233-6406

19 Mention of trade names or commercial products in this article is solely for the purpose of

20 providing specific information and does not imply recommendation or endorsement by

21 the U.S. Department of Agriculture. USDA is an equal opportunity employer.

23 Short Title (Running Head): Cold plasma inactivation of Norovirus surrogates 
24 Key Words: Cold plasma, inactivation, Norovirus, surrogate, blueberries, food safety 


\section{ABSTRACT}

27 Viruses are currently the leading cause of foodborne outbreaks, most of which are 28 associated with foods consumed raw. Cold plasma (CP) is an emerging novel nonthermal

29 technology that can be used to surface decontaminate foods. This study investigated CP

30 technology for the nonthermal inactivation of human norovirus surrogates, Tulane virus

31 (TV) and murine norovirus (MNV), on the surface of blueberries. Blueberries (5g) were

32 weighed into sterile 4 oz. glass jars and inoculated with TV, 5 log PFU/g. Samples were

33 treated with atmospheric $\mathrm{CP}$ for $0,15,30,45$, and $60 \mathrm{~s}$ at a working distance of $7.5 \mathrm{~cm}$

34 with 4 cubic feet/minute ( $\mathrm{cfm})$ of $\mathrm{CP}$ jet. Temperature readings were taken with an

35 infrared camera prior to, and immediately following, CP treatments. In order to establish

36 the impact of air flow during CP treatment $(4 \mathrm{cfm})$, an additional $7 \mathrm{cfm}$ jet of room

37 temperature air was introduced from a separate nozzle. The experiment was repeated with

3890 and 120 seconds as additional treatment time points. Viral titers were measured

39 immediately after each treatment with a plaque assay using LLC-MK2 cells (TV) or

40 RAW 264.7 cells (MNV). TV was significantly reduced $1.5 \mathrm{PFU} / \mathrm{g}$ compared to the

41 control after treatment time of $45 \mathrm{~s}$, which was achieved regardless of temperature

42 conditions. With the addition of $7 \mathrm{cfm}$ of ambient air, the maximum $\log$ reduction for TV

43 was $3.5 \log$ PFU/g after 120s of treatment. MNV was significantly reduced by $0.5 \log$

$44 \mathrm{PFU} / \mathrm{g}$ compare to the control at $15 \mathrm{~s}$, and further treatment of MNV with ambient air

45 brought the $\log$ reduction to greater than $5 \log$ PFU/g at $90 \mathrm{~s}$ of treatment (Fig 3). These

46 results demonstrate that $\mathrm{CP}$ viral inactivation does not rely on thermal inactivation, and is 
47 therefore nonthermal in nature. With further optimization, CP may be used by food

48 processors as a means of nonthermal inactivation of foodborne viruses.

\section{1. Introduction}

50 Consumption of blueberries has increased significantly in recent decades due to

51 their perceived health benefits (Zheng \& Wang, 2003). However, blueberries are

52 susceptible to contamination by biological hazards from pre-harvest to post-harvest

53 stages and are most commonly consumed raw. Human norovirus (HuNoV) is one of the

54 most common etiological agents that contaminates food and cause foodborne illness

55 (Scallan et al., 2011). A European Food Safety Authority (EFSA) panel has identified

56 that there have been 27 Norovirus outbreaks associated with berries between 2007 and

572011 (EFSA, 2014). While it is not possible to determine precisely when contamination

58 occurred in these outbreaks, it is believed that the greatest risks are likely to occur during

59 primary production as a result of environmental factors, use of sewage-contaminated

60 water, worker hygiene issues, or through cross-contamination (EFSA, 2014). Currently,

61 the preventative measures for viral outbreaks in the food supply chain primarily rely on

62 good agricultural practices, chemical washes, and increased awareness on good hygienic

63 practices in food handling areas (Scallan et al., 2011). However, few optimized

64 nonthermal intervention processes are available for fresh and fresh-cut produce; hence,

65 new intervention technologies are urgently needed.

66 Cold plasma (CP) is an emerging nonthermal technology that offers the advantage

67 of being chemical- and water-free, in addition to being able to operate openly and

68 continuously at atmospheric pressure (Niemira, 2012a). In the context of food processing

69 and food microbiology, although this technology may contribute thermal energy to 
70 treated commodities, it is commonly referred to as "cold", "cool", or "nonthermal"

71 plasma, based on the nonthermal nature of the antimicrobial modes of action observed,

72 rather than using terms based on plasma physics, such as "non-equilibrium" or "non-

73 Maxwellian"; however, the terminology associated with this relatively new class of

74 antimicrobial technologies is still being developed (Niemira, 2012a). Currently CP

75 technologies are utilized in other industries to modify the surface energy of polymers,

76 enhancing adhesion and printability. Recent studies have investigated the feasibility of

77 applying cold plasma to food surfaces (Lacombe, 2015). CP has demonstrated the

78 reduction of spoilage bacteria on the surface of blueberries with minimal effect on the

79 organoleptic properties (Pankaj et al., 2013; Lacombe, 2015).

80 Due to the non-cultivability of HuNoVs, potential surrogate microorganisms that

81 share pathological and/or biological features, such as feline calicivirus (FCV), murine

82 norovirus (MNV), coliphage MS2, Bacteroides fragilis phage B40-8, etc. have been used

83 (Cannon et al., 2012; Cannon, et al, 2006; D'Souza, 2010; Li, et al, 2013). FCV and

84 MNV have been widely used as such surrogates (Cannon et al., 2006, Li et al., 2013).

85 However, MNV has gradually been replacing FCV as a surrogate, due to its superior

86 resistant to acid and heat, and its ability to persistent in the environment (Cannon et al.,

87 2006; Li et al., 2013). The additional robustness of MNV may prove valuable to

88 investigators, however, MNV does not bind to the same receptors needed for infection as

$89 \mathrm{HuNoV}$. For HuNoV, human histo-blood group antigens (HBGAs) are proven to be the

90 receptors of the viruses (Huang et al., 2003) and play an important role as molecular

91 targets for the prevention of infection. Recently, the Tulane National Primate Research

92 Center reported the discovery of a new potential viral surrogate, Tulane virus (TV), that 
93 recognizes the type A and B HBGAs (Farkas, 2010). Due to these characteristics and its

94 closeness with HuNoV, TV could potentially serve as a surrogate for HuNoV. Recent

95 studies demonstrated that TV and MNV are both stable under heat, acidic and basic

96 conditions, and respond similarly to high pressure when inoculated on blueberries ( $\mathrm{Li}$ et

97 al., 2013).

98 Consumer demand for minimally processed fresh produce has created a challenge

99 for processors which aim to provide safe and adulterant-free products. Conventional

100 postharvest washing and sanitizers, such as chlorine-based treatments, can reduce cross-

101 contamination, but are not highly effective for reducing contamination on produce,

102 contributing less than $2 \log$ unit reductions of pathogens, and may leave residues (Crowe,

103 Bushway, \& Bushway, 2005; Kingsley et al., 2014; Wu and Rioux, 2010). CP treatment

104 was recently shown to inactivate potential spoilage microorganisms on blueberries

105 without effecting firmness, color, or anthocyanin concentration (Lacombe, 2015). In

106 addition to improving food safety, CP technologies are environmentally friendly and

107 sustainable, as they do not require on-site storage of supply chemicals or large volumes

108 of processing water, either for implementation or in post-treatment rinsing (Niemira,

109 2012a). The microbial inactivation effect of plasma treatment can be attributed to several

110 synergic mechanisms, including the generation of UV radiation, ozone, charged particles,

111 and oxygen radicals, in addition to other reactive species (Niemira, 2012a).

112 Little literature exists on CP application to reduce foodborne viruses. In studies

113 with argon plasmas, FCV in liquid suspension was reduced by up to $5 \log \mathrm{PFU} / \mathrm{g}$ after

114 treatment times of up to 300s (Aboubakr et al., 2015). Virucidal activity was enhanced by

115 addition of oxygen (Aboubakr et al., 2015). A study of the MS2 bacteriophage showed 
116 that a helium/oxygen-based CP process reduced that virus by $3 \log \mathrm{PFU} / \mathrm{g}$ at $120 \mathrm{~s}$

117 (Alshraiedeh et al, 2013). Ahlfed et al. (2015) showed that HuNoV in liquid suspension

118 was reduced by $1.69 \log$ after 15 minutes exposure to the cold plasma of an atmospheric

119 pressure mesh electrode system.

120 The objective of this work was to determine the effects of cold plasma processing

121 parameters (e.g., temperature and time) on the inactivation two HuNoV surrogates, TV

122 and MNV.

\section{2. Methods and materials}

\subsection{Blueberry Preparation}

126 Blueberries were obtained from the local grocery store and held at $4^{\circ} \mathrm{C}$ until use.

127 Prior to CP treatment, five blueberries per sample $(\sim 10 \mathrm{~g})$ were weighed out in sterile 4 128 oz. $(120 \mathrm{ml})$ clear, straight-sided glass jars, $60 \mathrm{~mm}$ diameter, $67 \mathrm{~mm}$ height, and $3 \mathrm{~mm}$

129 glass thickness. Blueberries were inoculated with $500 \mu \mathrm{l}$ of either TV or MNV and

130 vortexed for $1 \mathrm{~min}$ to ensure uniform coverage. After vortexing, the blueberries were

131 allowed to dry in a biosafety cabinet for 1 hour prior to treatment.

\subsection{Cold plasma treatment}

134 The equipment used was described by Niemira et al. (2012b). Briefly, a modified 135 version of a Dyne-A-Mite HP AC plasma jet device (Enercon Corp., Menomonee Falls, 136 Wis., USA) was used with an ionizing potential of $1 \mathrm{~cm}$ between two shaped electrodes 137 to generate a plasma arc within a Teflon cowling (Niemira, 2012b). Ambient air feed gas 138 set at 60 psi drove the plasma arc outward, allowing it to expand and cool. Based upon 
139 results from previous experiments, the plasma jet was adjusted to a pulse frequency of 47

$140 \mathrm{kHz}$, with a power consumption of $549 \mathrm{~W}$. The jars ( 5 berries per sample) were under the

141 CP apparatus with a working distance of $7.5 \mathrm{~cm}$ measured from the base of the Teflon

142 cowling to the outside base of the jar. The jars were treated either with 4 cubic

143 feet/minute atmospheric CP alone for $0,15,30,45,60,90$, and $120 \mathrm{sec}$, or with the CP

144 jet and $7 \mathrm{cfm}$ of ambient-temperature air, introduced via side nozzles. Average surface

145 temperature readings for the berries were taken with an infrared camera (Fluke Ti32,

146 Evrett,WA, USA) immediately after CP treatment (Fig. 1). Limit of detection post-

147 treatment was approximately $1.5 \log \mathrm{PFU} / \mathrm{g}$.

$148 \quad 2.3$ Virus propagation and cell lines

149 MNV strain (MNV-1), murine macrophage cell line RAW 264.7, TV, and

150 monkey kidney cell line LLC-MK2 were used in these studies. MNV was propagated in

151 RAW 264.7 cells and were cultured in high-glucose Dulbecco's modified Eagle medium

152 (DMEM) (Life Technologies, Carlsbad, CA) supplemented with 30\% fetal bovine serum

153 (FBS, heat-inactivated, $<0.05 \mathrm{EU} / \mathrm{ml}$ endotoxins), GlutaMax, and $1 \%$

154 penicillin/streptomycin (100 U/ml) (Life Technologies). MNV stock (approximately 6

$155 \log$ PFU/ml) was prepared by infecting $(\mathrm{MOI}=1)$ a RAW 264.1 cell monolayer $(90 \%$

156 confluence over $150 \mathrm{~cm}^{2}$ ). After $1 \mathrm{~h}$ of incubation at $37^{\circ} \mathrm{C}$ under a $5 \% \mathrm{CO}_{2}$ atmosphere,

$15725 \mathrm{ml}$ of DMEM supplemented with 30\% FBS was added. MNV-1 was harvested 2 days

158 after post-inoculation by three freeze-thawing cycles, centrifugation, and $0.22 \mu \mathrm{m}$

159 filtration (Li e al., 2013).

160 TV was propagated in MK2-LLC cells that were cultured in M199 medium (Life

161 Technologies) supplemented with 10\% FBS (Life Technologies) and 
162 penicillin/streptomycin $(100 \mathrm{U} / \mathrm{ml})$. The same procedures were followed to grow TV

163 except that cells were infected with TV at a MOI of 0.1 and M199 supplemented with

$16410 \%$ FBS was used after $1 \mathrm{~h}$ incubation period. Both cells were cultured at $37^{\circ} \mathrm{C}$ under a

$1655 \% \mathrm{CO}_{2}$ atmosphere. Virus was stored at $-80^{\circ} \mathrm{C}$ until use.

1662.4 Viral plaque assay

167 After treatment with CP, the virus samples were recovered from the 5 berries per 168 sample in $10 \mathrm{ml}$ of either M199 (TV) or DMEM (MNV) through vortexing agitation on

169 high for one min. This method ensures a 90\% recovery and that the berries stay whole so

170 that the native polyphenols do not interfere with the plaque assay. The liquid was

171 recovered using a pipette and filtered through a $0.22 \mu \mathrm{m}$ filter (EMD Millipore, Billerica,

172 MA). Limit of detection post-treatment was approximately $1.5 \log$ PFU/g. MNV-1 and

173 TV were quantified by serial dilution plaque assay procedures by Li et al. (2013) with

174 slight modifications. For MNV-1, 24 hour prior to infection RAW 264.7 cells were

175 seeded into six-well plates (Becton, Dickinson and Company, Franklin Lakes, NJ) at a

176 density of $2 \times 10^{6}(6.3 \mathrm{log})$ cells per well. After incubation, cell monolayers were infected

177 with $400 \mu \mathrm{l}$ virus samples in duplicate. After a 1 hour incubation at $37^{\circ} \mathrm{C}$ and $5 \% \mathrm{CO}_{2}$,

178 cells were overlaid with $4 \mathrm{ml}$ of minimum essential medium (MEM) containing $0.5 \%$

179 agarose, $30 \% \mathrm{FBS}, 0.12 \%$ sodium bicarbonate, penicillin G (100 U/ml), streptomycin

$180(100 \mu \mathrm{g} / \mathrm{ml})$, and amphotericin B $(0.25 \mu \mathrm{g} / \mathrm{ml}), 25 \mathrm{mM}$ HEPES (pH 7.7), and $2 \mathrm{mM} \mathrm{l-}$

181 glutamine (Life Technologies). TV was quantified using a monolayer of LLC-MK2 cells

182 at a density of $4 \times 10^{5}$ cells per well. After incubating for 24 hours, cell monolayers were

183 infected with $400 \mu \mathrm{l}$ virus samples in duplicate. Cells were overlaid with $2 \mathrm{ml}$ of M199

184 medium, $10 \%$ fetal bovine serum, penicillin $\mathrm{G}(100 \mathrm{U} / \mathrm{ml})$, streptomycin $(100 \mu \mathrm{g} / \mathrm{ml})$, and 
185 amphotericin B $(0.25 \mu \mathrm{g} / \mathrm{ml})$, and $0.5 \%$ agarose. Plates infected with MNV were

186 incubated for 2 days and plate containing TV were incubated for 4 days, both at $37^{\circ} \mathrm{C}$ and

$1875 \% \mathrm{CO}_{2}$ before enumeration. After incubating, plates were fixed in $3.7 \%$ formaldehyde

188 (Fisher Scientific, Pittsburg, PA) and the plaques were visualized by staining with 0.05\%

189 (w/v in $10 \%$ ethanol) crystal violet.

1912.5 Statistical analysis

192 Treatments were performed in three independent replications of five berries each,

193 with two subsamples taken from each replication. Reductions of viral surrogates (log

$194 \mathrm{PFU} / \mathrm{g})$ by CP were calculated based on the pooled data $(\mathrm{n}=6)$. Mean comparisons were

195 made between the untreated control and each treatment using ANOVA, with Fisher's

196 least significant difference to determine significance $(\mathrm{P}<0.05)$.

198 3. Results and discussion

199 This is the first study that investigates the inactivation of HuNoV viral surrogates

200 on blueberries by CP while considering the effect of temperature on reduction. The

201 results from this study indicate that $\mathrm{CP}$ has the potential as a postharvest decontamination

202 step for viruses. Previous research, using the device described herein, showed that where

203 the plasma plume was allowed to expand, the temperature of the treated product remained

204 well below the minimal level of thermal kill for enteric pathogens and HuNoV (viz., ca.

$20558-60^{\circ} \mathrm{C}$ ) (Niemira 2012b; Bozkhurt et al, 2013). In contrast, for berries treated in the

206 enclosed vessel used in the present study, temperatures rose above this level (Fig 2). For

207 berries treated with $\mathrm{CP}$ alone, thermal damage to the berries occurred after treatments of 
20860 s, when temperatures reached $>70^{\circ} \mathrm{C}$. As this resulted in significant loss of mechanical

209 integrity, the CP-alone treatments were discontinued for treatments longer than 60s. In

210 contrast, however, introduction of ambient-temperature air via flanking nozzles

211 effectively mitigated this thermal accumulation effect. The process, conducted at

212 temperatures well below the level of thermal kill for norovirus surrogates (Bozkhurt et al,

213 2013), nevertheless, achieved significant $(\mathrm{p}<0.05)$ inactivation of viral titers. The CP

214 process is, therefore, shown to be nonthermal in nature. TV was significantly reduced by

$2151.5 \mathrm{PFU} / \mathrm{g}$ compared to the control after treatment time of $45 \mathrm{~s}$, which was achieved

216 regardless of temperature conditions (Fig 2). With the addition of $7 \mathrm{cfm}$ of ambient air,

217 the maximum log reduction for TV was $3.5 \log \mathrm{PFU} / \mathrm{g}$ after $120 \mathrm{~s}$ of treatment. MNV was

218 significantly reduced by $0.5 \log \mathrm{PFU} / \mathrm{g}$ compare to the control at $15 \mathrm{~s}$, and further

219 treatment of MNV with ambient air brought the log reduction to greater than $5 \log \mathrm{PFU} / \mathrm{g}$

220 at $90 \mathrm{~s}$ of treatment (Fig 3).

221 The inability to propagate $\mathrm{HuNoV}$ in vitro precludes direct determination of

222 inactivation, therefore propagable genetically-related surrogates (MNV and TV) with

223 similar biophysical properties were utilized to assess surface decontamination and

224 virocidal efficacy. The majority of chemical disinfection studies and studies on

225 processing interventions have been carried out using FCV and MNV (Ahlfeld, 2015;

226 Baert, 2009). However, the susceptibility of FCV and MNV to different treatments varies

227 considerably. FCV is less tolerant of low and high $\mathrm{pH}$ when compared to MNV (Cannon

228 et al., 2006). MNV demonstrated more susceptibility to alcohol based hand sanitizers

229 than FCV (Sattar, 2011). Also, in studies with argon/oxygen plasmas, FCV demonstrated

230 notably higher sensitivity to $\mathrm{CP}$ than the surrogates used herein (Aboubakr et al., 2015). 
231 Therefore, inferences drawn from surrogates regarding the response of HuNoV to $\mathrm{CP}$ are

232 contingent on a clear understanding of mechanism of inactivation, and should be made

233 judiciously. The present study demonstrates that MNV was more susceptible to CP

234 treatments than TV, with MNV demonstrating significant reduction after $15 \mathrm{sec}$ in

235 comparison to TV demonstrating significant reduction at $45 \mathrm{sec}$. TV's HBGA binding

236 properties, which are similar to $\mathrm{HuNoV}$, may be important for its increased resistance to

237 CP treatment. The inactivation mechanisms for virus disinfectants are not well-defined

238 and, for enteric virus, there are two potential inactivation targets - the virus genome and

239 the capsid. CP presents a complex mode of action, as it generates a combination of

240 photoinactivating light, gaseous antimicrobials, and reactive species (Niemira 2012a).

241 Each of these can act on both the viral capsid and genome (Niemira, 2012b). In addition,

242 intrinsic factors such as water activity, texture, and protein and fat content can

243 dramatically alter the antimicrobial effects of CP and the sensory properties of the treated

244 product. The proposed mechanism in which ozone and ROS inactivate viruses involves

245 first the damage of polypeptide chains causing a perforation in the viral capsid (Kim, and

246 Sproul, 1980; Roy, 1981). The inactivation of viruses by ozone is rate limited by the

247 diffusional step of ROS through the protein coat into the nucleic acid core, where damage

248 to the RNA ultimately prevents infection (Roy et al., 1981; Kim et al., 1980).

249 CP can efficiently kill or inactivate yeasts and molds and other hazardous

250 microorganisms, even spores and biofilms that are generally difficult to inactivate

251 (Niemira, 2012a). The logarithmic reduction of Escherichia coli O157:H7 and

252 Salmonella Typhimurium biofilms on agar surfaces and on food products has been

253 demonstrated after short treatments with CP (Niemira, 2012a, 2012b). Recent studies 
254 demonstrated the capability of $\mathrm{CP}$ as a postharvest sanitation process. When applied to

255 blueberries, native microflora were reduced immediately after treatment, and were

256 suppressed during refrigerated storage of up to 7 days (Lacombe et al., 2015). Treatment

257 conditions in that study which effectively reduced aerobic bacteria on the surface of

258 blueberries did not adversely affect texture or cause significant loss of anthocyanins

259 (Lacombe et al., 2015).

260 Contact times of 60s and 120s are standard industry practice for chemical washes during

261 blueberry line processing, and CP demonstrated virucidal effect well within those

262 parameters, regardless of surrogate (Crowe et al., 2005). The capability of CP as a

263 postharvest sanitation process was demonstrated by reducing human pathogens such as $E$.

264 coli O157:H7, Salmonella, L. monocytogenes, S. aureus, and Shigella spp. (Niemira,

265 2012a). Many methods for removing pathogens as well as minimizing their effect on the

266 quality of treated produce have been investigated. The efficacy of an electrostatic spray

267 of electrolyzed oxidizing water, UV light, ozone, and a combination of ozone and UV

268 light in inactivating Escherichia coli $\mathrm{O} 157: \mathrm{H} 7$ was studied on blueberries (Kim \& Hung,

269 2012). Combinatorial treatments of ozone and UV had demonstrated more efficacy in

270 killing microorganisms on the calyx of blueberries than UV alone or ozone treatments

271 alone indicating a synergistic effect (Kim \& Hung, 2012). CP has the potential of being a

272 more economic delivery mechanism of antimicrobial treatments, especially if ambient air

273 is used as its feed gas (Niemira, 2012a). As this technology moves closer to commercial

274 viability, further research is required to more fully elucidate the mode(s) of action of this

275 type of cold plasma system. Detailed chemical analyses, based on emission spectroscopy,

276 absorption spectroscopy, and related methods, will assist in optimization of CP for a 
277 wider range of fresh and fresh-cut fruits and vegetables (Niemira, 2012a; Min et al,

278 2016). The present study demonstrates a lab-scale CP system to inactivate viruses on the

279 surface of blueberry in conjunction with force air cooling. Previous studies demonstrated

280 that, when using the injected cooling air, this system had no significant impact on the

281 firmness, color, or anthocyanins concentration following minimum treatment times

282 necessary to inactivate the viral surrogates. Optimization and scale-up to commercial

283 treatment levels will require a more complete understanding of these chemical processes

284 and mechanism of viral inactivation. The short time of treatment necessary for

285 inactivation and limited deterioration of the product suggest that CP technologies may

286 offer advantages with regard to adaptation for existing processing facilities for

287 postharvest, prepackage, and in-package decontamination treatment of foods.

289 Acknowledgments

290 The authors acknowledge USDA National Institute of Food and Agriculture, NIFA

291 Award No: 2011-68003-30005.

292

293

294

295 
References:

Aboubakr, H.A., Williams, P., Gangal, U., Youssef, M.M., El-Sohaimy, S.A.A., Bruggeman, P.J., Goyal, S.M., 2015. Virucidal effect of cold atmospheric gaseous plasma on feline calicivirus, a surrogate for human norovirus. Appl. Environ. Microbiol. 81, 3612-3622.

Ahlfeld, B.L., Yangfang, L., Boulaaba, Y., Binder, A., Schotte, A., Zimmermann, U., Morfill, J., Kleina, G., 2015. Inactivation of a foodborne norovirus outbreak strain with nonthermal atmospheric pressure plasma. mBIO. 6, 1-6.

Alshraiedeh, N.H., Alkawareek, M.Y., Gorman, S.P., Graham, W.G., Gilmore, B.F., 2013. Atmospheric pressure, nonthermal plasma inactivation of MS2 bacteriophage: effect of oxygen concentration on virucidal activity. J. Appl. Microbiol. 115, 1420-1426.

309 Baert, L.D., Uyttendaele, M., 2009. The efficacy of preservation methods to inactivate 310 foodborne viruses. Int. J. Food Microbiol. 131, 83-94.

311 Bozkurt H., D'Souza, D.H, Davidson, P.M., 2013. Determination of the thermal inactivation kinetics of the human norovirus surrogates, murine norovirus and

314 Cannon, J. L., Aydin, A., Mann, A.N., Bolton, S.L., Zhao, T., Doyle, M. P., 315 2012. Efficacy of a levulinic acid plus sodium dodecyl sulfate-based sanitizer on 316 inactivation of human norovirus surrogates. J. Food Prot. 75, 1532-1535. 
317 Cannon, J.L.P., Park, G.W., Osborne, J., Jaykus, L.A., Vinje, J., 2006. Surrogates for the

318 study of norovirus stability and inactivation in the environment: a comparison of murine norovirus and feline calicivirus. J. Food Prot. 69, 2761-2765.

320 Crowe, K.M., Bushway, A.A., Bushway, R.J., 2005. Effects of Alternative Postharvest Treatments on the Microbiological Quality of Lowbush Blueberries. Small Fuits

D'Souza, D.H.S., 2010. Efficacy of chemical treatments against murine norovirus, feline Rev., 4, 29-39.

325 326 calicivirus, and MS2 bacteriophage. Foodborne Path. Dis. 7, 312-317.

EFSA, 2014. Scientific Opinion on the risk posed by pathogens in food of non-animal origin. Part 2 (Salmonella and Norovirus in berries). EFSA Journal. 12, 3600 Available at: http://www.efsa.europa.eu/en/efsajournal/pub/3600 (accessed 9.23.15).

Farkas T., Cross, R.W., Hargitt, E., Lerche, N.W., Morrow, A.L., Sestak, K., 2010. Genetic diversity and histo-blood group antigen interactions of rhesus enteric caliciviruses. J. Virol. 84, 8617-8625.

Huang, P., Farkas, T., Marionneau, S., Zhong, W., Ruvoen-Clouet, N., Morrow, A.L., Altaye, M., Pickering, L.K., Newburg, D.S., LePendu, J., Jiang, X., 2003. Noroviruses bind to human ABO, Lewis, and secretor histo-blood group antigens: identification of 4 distinct strain-specific patterns. J. Infect. Dis. 188, 19-31.

Huang P., Farkas, T., Zhong, W., Tan, M., Thornton, S., Morrow, A.L., Jiang, X. 2005, Norovirus and histo-blood group antigens: demonstration of a wide spectrum of strain specificities and classification of two major binding groups among multiple binding patterns. J. Virol. 79, 6714-22. 
340 Kim, C., Hung, Y.-C., 2012. Inactivation of E. coli O157:H7 on Blueberries by

341 Electrolyzed Water, Ultraviolet Light, and Ozone. J. Food Sci. 77, 206-211.

342 Kim, C.K., Gentile, D.M., Sproul, O.J., 1980. Mechanism of ozone inactivation of

343 bacteriophage f2. Appl. Environ. Microbiol. 39, 210-218.

344 Kingsley, D.H., Vincent, E.M., Meade, G.K., Watson, C.L., Fan, X., 2014. Inactivation

345 of human norovirus using chemical sanitizers. Int. J. Food Microbiol., 171, 94-99.

346 Lacombe, A., Niemira, B.A., Gurtler, J.B., Fan, X., Sites, J., Boyd, G., Chen, H., 2015.

347 Atmospheric cold plasma inactivation of aerobic microorganisms on blueberries

348 and effects on quality attributes. Food Microbiol. 46, 479-484.

349 Li, X., Ye, M., Neetoo, H., Golovan, S., Chen, H., 2013. Pressure inactivation of Tulane

350 virus, a candidate surrogate for human norovirus and its potential application in

351 food industry. Int. J. Food Microbiol. 166, 102-108.

352 Min, S., Roh, S.H., Niemira, B.A., Sites, J.E., Boyd, G., Lacombe, A., 2016. Dielectric

353 barrier discharge atmospheric cold plasma inhibits Escherichia coli O157:H7,

354 Salmonella, Listeria monocytogenes, and Tulane virus in Romaine lettuce. Int J

$355 \quad$ Food Microbiol. 237, 114-120

356 Niemira, B. A., 2012a. Cold plasma decontamination of foods. Ann. Rev. Food Sci.

$357 \quad$ Technol. 3, 125-142.

358 Niemira, B.A., 2012b. Cold plasma reduction of Salmonella and Escherichia coli

359 O157:H7 on almonds using ambient pressure gases. J. Food Sci., 77, 171-175.

360 Pankaj, S.K., Bueno-Ferrer, C., Misra, N.N., Milosavljević, V, O’Donnell, C.P., Bourke,

361 P., Keener, K.M., Cullen, P.J., 2013. Applications of cold plasma technology in

362 food packaging. Trends Food Sci. Technol. 35, 15-17. 
363 Roy, D. W., Wong, P.K., Englebrecht, R.S., Chian, E.S., 1981. Mechanism of enteroviral

364 inactivation by ozone. Appl. Environ. Microbiol, 41, 718-723.

365 Sattar, S.A.A., Ali, M., Tetro, J.A., 2011. In vivo comparison of two human norovirus

366 surrogates for testing ethanol-based handrubs: the mouse chasing the cat! PLoS

367 ONE. 6, e17340.

368 Scallan, E., Hoekstra, R.M., Angulo, F.J., Tauxe, R.V., Widdowson, M.A., Roy, S L.,

369 Griffin, P.M., 2011. foodborne illness acquired in the united states-major

370 pathogens. Emerg. Infect. Dis., 17, 7-15.

371 Wu, V.C.H., Rioux, A., 2010. A simple instrument-free gaseous chlorine dioxide method

372 for microbial decontamination of potatoes during storage. Food Microbiol. 27,

$373 \quad 179-184$.

374 Zheng, W., Wang, S.Y., 2003. Oxygen radical absorbing capacity of phenolics in

375 blueberries, cranberries, chokeberries, and lingonberries. J. Agric. Food Chem.,

$376 \quad 51,502-509$.

377

378 
379 Figure Legends:

380 Figure 1: Thermal images of cold plasma treatment: $4 \mathrm{cfm}$ plasma jet plus $7 \mathrm{cfm}$ air

382 Figure 2: Inactivation of Tulane virus (TV) using cold plasma (with or without $7 \mathrm{cfm}$

383 ambient air). Left axis represents viral titer. Right axis represents temperature

384 immediately after treatment. Asterisk $(*)$ for a given treatment time indicates significant

$385(P<0.05)$ difference from control. Error bars indicate standard error.

387 Figure 3: Inactivation of Murine norovirus (MNV) using cold plasma (with or without

$3887 \mathrm{cfm}$ ambient air). Left axis represents viral titer. Right axis represents temperature

389 immediately after treatment. Asterisk $(*)$ for a given treatment time indicates significant $390(P<0.05)$ difference from control. Error bars indicate standard error. 
393 Figure 1.

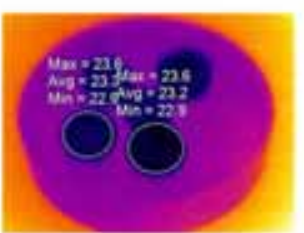

Control $\left(23.2^{\circ} \mathrm{C}\right)$

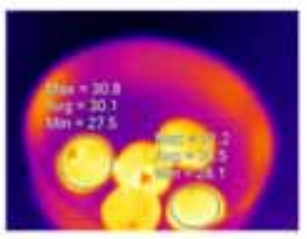

$15 \sec \left(30.1^{\circ} \mathrm{C}\right)$

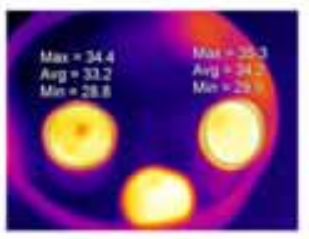

$30 \sec \left(34.2^{\circ} \mathrm{C}\right)$

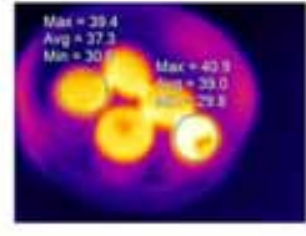

$45 \sec \left(39.0^{\circ} \mathrm{C}\right)$

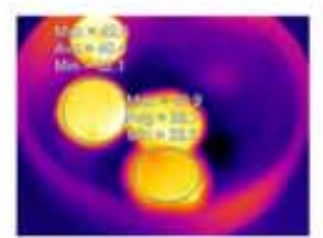

$60 \sec \left(40.4^{\circ} \mathrm{C}\right)$

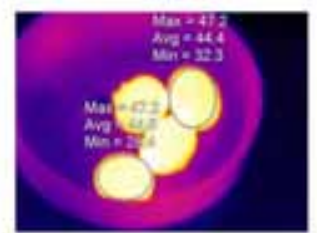

$90 \sec \left(44.4^{\circ} \mathrm{C}\right)$

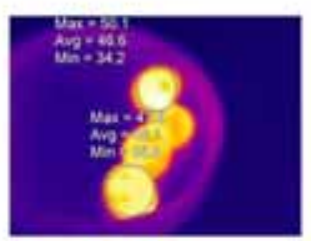

$120 \sec \left(46.6^{\circ} \mathrm{C}\right)$

394

395 
Figure 2.

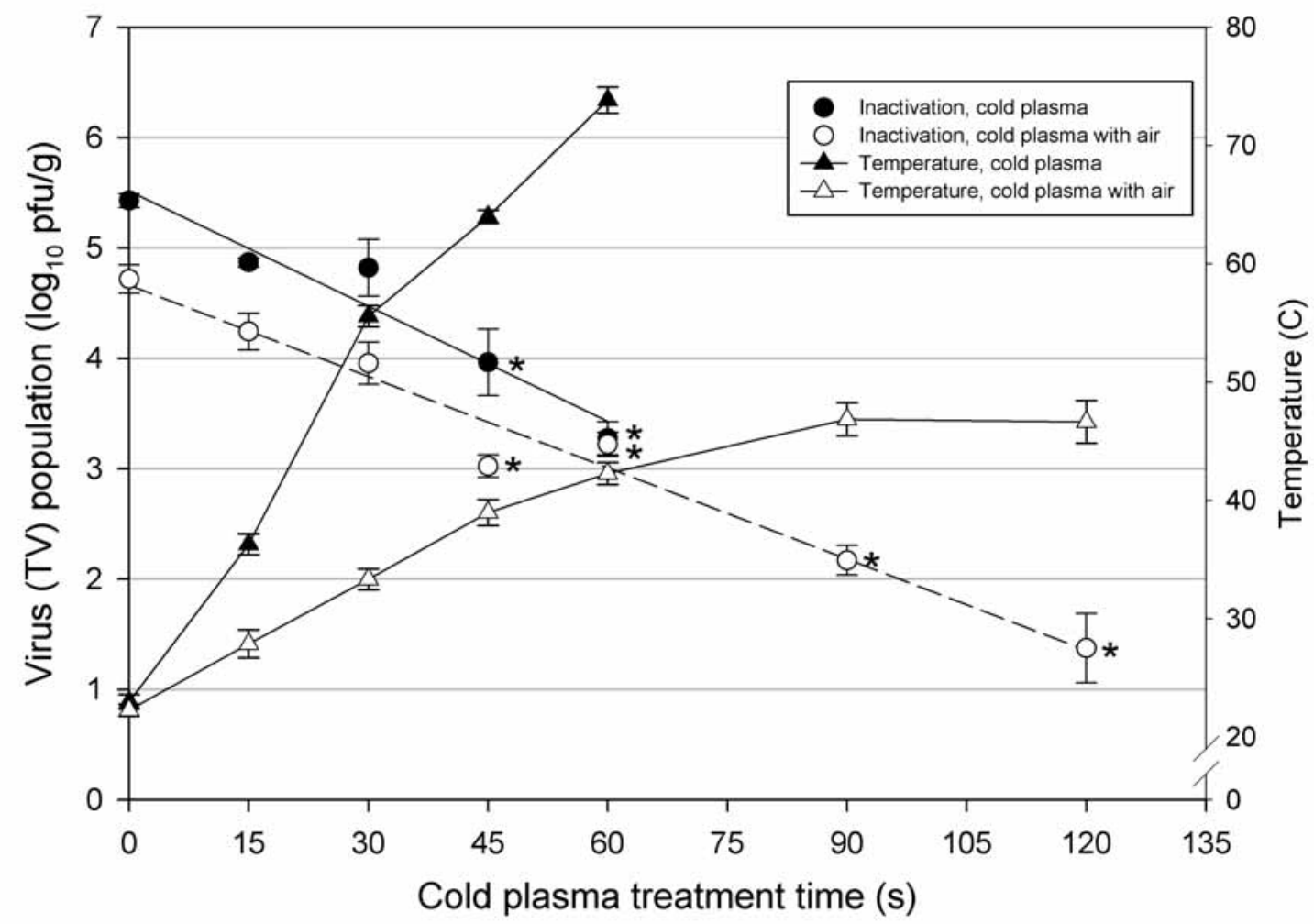

397 
Figure 3.

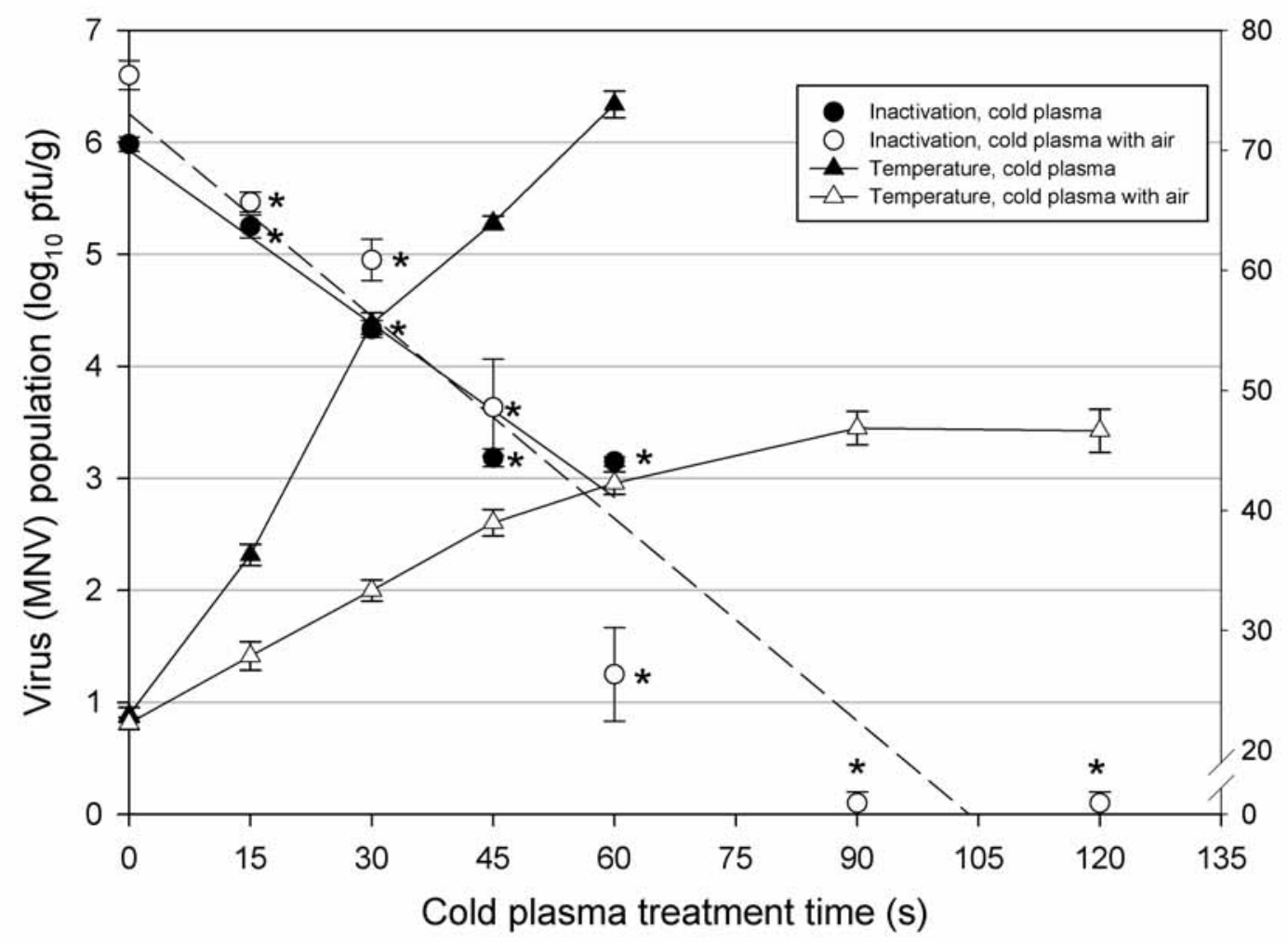

400

401

402 